\title{
Post Disaster Reconstruction in Sindhupalchok after Earthquake 2015: Problem and Prospects
}

\author{
Top Bahadur Dangi \\ Deputy Superintendent of APF, Nepal \\ Student Officer, $2^{\text {nd }}$ APF Command and Staff Course \\ Email: dangitop7@gmail.com
}

\begin{abstract}
This research has been carried out amidst of delay accomplishment of Post Disaster Reconstruction (PDR) to find out the problem and prospect of PDR in Sindhupalchowk. All data has been collected from primary and secondary source. Data from secondary source, National Reconstruction Authority, field visit and FGD has been incorporated as par requirement. Qualitative and quantitative data analysis was the main instrument for this study. The frequency, intensity, severity and ramification of disaster are increasing day by day. The number of dead, injured, displaced and damage is also increasing. Disaster is becoming a great threat for human, social, economic and environmental sustainability and for development. PDR is a program of recovery and rehabilitation phase of disaster management where actions taken to restore and improve pre-disaster living condition of affected communities. PDR is usually slow, expensive, complex and controversial issue which gives positive result only if it is carried out in well managed, transparent and participatory approach. Build back better and linking reconstruction with development and economic activities are the fundamental and essential element of successful reconstruction. Socioeconomic condition of people can be enhanced by adopting appropriate measure in PDR.

After earthquake 2015, NRA has been established and is working all over the affected area of Nepal. Sindhupalchok is one of the most affected districts by earthquake 2015, where NRA has launched its reconstruction program which is in progress but is not as successful as expected before. Political instability, bureaucratic inefficiency, lack of sufficient finance, trained human resource and construction material, poverty and noncompliance of people are major reason behind the delay accomplishment of PDR. Government has to execute its policy strictly and people also have to be cooperative towards the government policy and should reconstruct their house according to the guidelines of NRA within given timeframe.
\end{abstract}

Keyword: Disaster, earthquake 2015, PDR, NRA, build back better

\section{Introduction}

The term disaster is originated from the French word "Des-astre" which is a combination of two words 'des' meaning bad and 'aster' meaning star. Thus the term refers to 'Bad or Evil star'. According to the Natural Disaster Relief Act 1982, natural disaster means earthquake, fire, flood, landslide, heavy rain, drought, famine, epidemic and other similar natural disaster. It includes the industrial accident or accident caused by the explosions or poisoning and any other kinds of disaster. According to UNISDR Terminology on DRR (2009), the serious disruption of the functioning of society, causing widespread human, material or environmental losses, which exceed the ability of the affected people to cope up by using their own resources, is known as disaster.

Disaster Management means a continuous and integrated process of planning, organising, coordinating and implementing measures which are necessary for prevention of danger or threat of any disaster. Frequency, severity and intensity of disasters are increasing day by day and 
Dangi: Post Disaster Reconstruction in...| 22

in consequences the death, injury, displacement and damage is also increasing, in this context disaster risk reduction is most essential tool to cope up the disaster and its effects.

There are mainly four steps in disaster management cycle which can be divided into two groups one is pre disaster activities and another is post disaster activities. Mitigation and preparedness is pre disaster activities and response and recovery are post disaster activities. Prevention is better than cure so, emphasis should be given to preventive activities. More focus should be given to prevention, preparedness and mitigation to avoid, minimize the effect and can operate response, relief and recovery activities easily and effectively.

\section{Nepal Earthquake 2015}

Earthquake of 2015 was severe earthquake that struck mountain and Himalayan region of central Nepal on April 25, 2015. The earthquake was felt throughout central and eastern Nepal, much of the Ganges River plain in northern India and north-western Bangladesh, as well as in the southern parts of the Plateau of Tibet and western Bhutan.

The initial shock, which registered a magnitude of 7.8, struck shortly before noon local time. Its epicentre was about $34 \mathrm{KM}$ east-southeast of Lamjung and $77 \mathrm{KM}$ northwest of Kathmandu and its hypocenter was about $15 \mathrm{~km}$ underground. Two large aftershocks, with magnitudes 6.6 and 6.7, shook the region within one hour of the main quake and several dozen smaller aftershocks occurred in the region during the succeeding days. About 9,000 people were killed, many thousands were injured and more than 700,000 structures in Kathmandu and other nearby towns were either damaged or destroyed (Rafferty, 2017).

\section{National Reconstruction Authority and Post Disaster Reconstruction}

After earthquake 2015 Government of Nepal has established National Reconstruction Authority (NRA) to work solely in the field of reconstruction. It has responsibility to collect the assistance from different international community, make an appropriate policy for reconstruction and work for an effective implementation for reconstruction of affected area of Nepal. It is working since establishment but in a slow pace with many hurdle and criticism. The desired output has not been materialized in the field. People are still living in temporary house in difficult situation. They are suffering from lack of all kinds of public service and they are waiting for support. Apart from NRA, NGOs, INGOs and other agencies are also working for the same cause but reconstruction work is not happening in smooth and effective manner.

NRA has been established to reconstruct the public and private building and to resettle the displaced victims. It has been established on 10th Paush 2072. Its main task is to prepare policy and program for reconstruction and implementation of that policy. It provides leadership for completing reconstruction and works for coordinating national and international stakeholder. It works together with multiple partners in central and local level to accelerate the reconstruction program in effective manner. The reconstruction is the process of building or creating something again that has been damaged or destroyed. Reconstruction is sometime defined as the process of making a country normal again after a war or mega disaster by making the economy stronger and by replacing buildings that have been damaged. Post Disaster Reconstruction is not merely a housing solution, but a complex and multidimensional process. Post Disaster Reconstruction can be utilised as opportunity for build back better and for enhancing socio-economic condition of people.

According to Roosli, Vebry, Mydin and Ismail (2012) reconstruction is assessed, planned and implemented in gradual stages. He suggested that Post Disaster Reconstruction (PDR) require 


\section{3 | Journal of APF Command and Staff College}

existing tools or new tools to be adapted that if not well planned and implemented, can create further vulnerabilities in a disaster-affected community. Post-disaster reconstruction often deals with uncertainties and complexity which is one of the most challenging tasks to deal with after disaster. Post-disaster reconstruction and rehabilitation is a complex issue with several dimensions. PDR is very costly, complex, comprehensive and time consuming effort (Bang, 2012).

The PDR initiative is part of a sequence of four identifiable post disaster periods: emergency, restoration, reconstruction and betterment construction (Ye \& Okada, 2002). Poor plan and implementation of PDR can create further vulnerabilities in a disaster-affected community. Planning for reconstruction from a disaster must be realistic and reflective. Without a plan, it is impossible to predict or expect a successful recovery. The post-disaster context is characterized by a lack of access, logistical issues and inadequate human resources. Reconstruction efforts may be additionally hampered through institutional bureaucracy, corruption, inadequate coordination, inexperience of construction management and pressures from government and humanitarian agencies for quick project completion. In terms of the implementation of housing reconstruction, issues of community participation, communication, resettlement and the cultural appropriateness of recovery measures have been a recurring challenge and continue to cause housing reconstruction projects to fail. All of these challenges must be adequately managed in order to have a successful reconstruction program (Iuchi, 2010).

There are two distinct concepts used for post-disaster housing reconstruction, namely, the donordriven and owner-driven approaches. It has been revealed that beneficiary satisfaction is higher on owner-driven approach compared to the donor-driven approach. Non-availability of suitable land and capacity constraints of the construction industry are identified as critical factors affecting the success of donor-driven housing programme. It was assumed that the quickest and most effective way to rebuild houses after a disaster is to employ the "donor-driven" approach, where the government or an external funding agency leads the reconstruction process with the help of consultants and contractors procured for the project (Karunasena \& Rameezdeen, 2010).

\section{Post Disaster Reconstruction in Nepal}

Nepal is practicing the Post Disaster Reconstruction program after earthquake 2015. Powerful and separate NRA has been established for the purpose but it is under criticism because it is not functioning in a successful manner to overcome the sorrow of affected people in expected time. With significant actors involved in the reconstruction process, no appreciable relief has reached to the ground, which is reflected over the frustration of affected people. Inaccessibility, absence of local government, weak governance, weak infrastructures, lack of preparedness, knowledge gap and manpower shortage etc. are the key challenges of the reconstruction after 2015 earthquake in Nepal (Sharma \& KC, 2017).

The lack of funding, construction materials, labors and experienced human resources hinder the smooth progress of reconstruction. Similarly, reconstruction projects can take place only when the affected people are also involved in the design and planning process as well as in the implementation phase of the project, ensuring the best utilization of local knowledge and resources as much as possible. The strong coordination among various stakeholders can act as the key to an effective reconstruction in the context of Nepal (Dhungana, Dahal, Shrestha, Thapa \& Neupane, 2017).

NRA is mainly engaging in policy making, coordination, fund raising, recording, monitoring and evaluation of reconstruction and resettlement program of affected district. NRA has policy of providing Rs 300000 cash in three instalments, more Rs 300000 debts without interest, Rs 200000 
cash for those who does not have land for safe building and free technical assistance. Recently government has made announcement to provide additional Rs 100000 to each beneficiary.

Even after two and half year of earthquake only around 5 percentage of beneficiaries has been provided third phase of grant. The gap between the beneficiaries who received first phase and second phase of grant is also very high. Only around 12 percentage of damaged house has been reconstructed and more 36 percentage houses are in the process of reconstruction so far. It shows initial phase of reconstruction was very slow whereas latest progress shows that the speed is increasing gradually.

Besides private housing construction, NRA is engaged in construction of other public infrastructure also. Public services like school, health post, water system etc. are constructing by different agency in coordination with NRA. Public service infrastructures are more crucial to be constructed in time but the completion rate of public service infrastructure is not satisfactory. Although it is faster than the construction rate of private house, only around 60-70 percentage of infrastructure has been completed. I/NGO and Urban Development and Building Construction Office are engaged for public service infrastructure reconstruction.

\section{Effect of Earthquake 2015 in Sindhupalchok}

Sindhupalchok is mountainous district with high vulnerability of natural disaster like landslide, earthquake, avalanche etc. Uneven geography, high slope, unsafe settlement pattern, illiteracy, poverty, negligence etc are some of the factor due to which Sindhupalchok can be considered as highly disaster prone district of Nepal.

Sindhupalchok is one of the worst affected districts as a result of the earthquake that took place on the 25th April 2015. While the initial epicenter of the earthquake was in Gorkha district, the highest magnitude (6.7) aftershock took place in Sindupalchok. The district has most number of deaths and injuries. Among fourteen most effected districts, Sindhupalchok is in number one position in regards to death toll. Kathmandu, Nuwakot, Dhading and Gorkha are other next most affected districts of Nepal. Number of injured and displaced is also very high in Sindhupalchok.

Among 9,000 deaths, 3,532 people had been killed only in Sindhupalchok which was highest fatality among other district. Thousands of houses, public and private school buildings, government office buildings, historical, cultural and archaeological heritages had been seriously damaged and many people rendered homeless. As far as number of infrastructure destruction is concern, Sindhupalchok comes again in number one position. Dhading, Nuwakot, Dolakha and Gorkha are other districts faced heavy devastation by earthquake 2015 .

\section{Post Disaster Reconstruction in Sindhupalchok after Earthquake 2015}

PDR is entering in the third year of reconstruction; many of the same problems continue to hinder the efforts to extend helping hands to thousands of survivors. NRA Office is there in Sindhupalchok and is devoted to contribute in reconstruction since its inception. The overall reconstruction result is same as other district of Nepal. Problem, issue and hindrances for unsatisfactory reconstruction are similar all over Nepal.

The amount provided by government is less than half to build the house because most of the beneficiaries have been invested more than seven lakhs for reconstruction of their house. Most of the beneficiaries pointed out the insufficiency of grant, the major challenges for PDR. They are expecting the adjustment of PDR and increments of grant. 
The present situation of PDR in Sindhupalchok is very slow and only around 12 percentage of houses have been reconstructed, about 38 percentage of houses have been in progress of reconstruction and remaining are still in initial phase of reconstruction. The gap between first phase grant recipients and third phase grant recipients is very high which is similar as national average.

Figure 1: Present Situation of PDR in Sindhupalchok (2018, Jan 5)

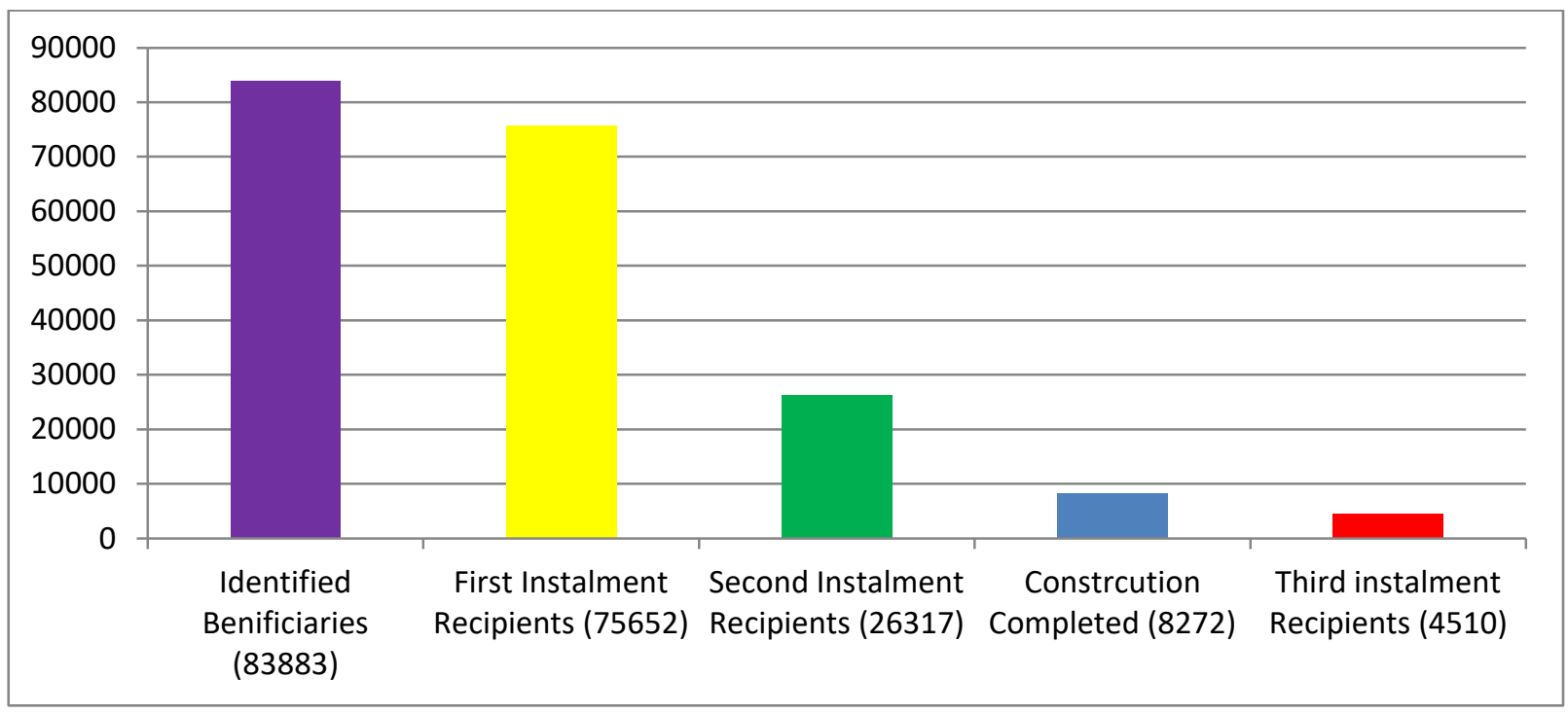

Source: http://nra.gov.np/mapdistrict/datavisualization

\section{Problem of PDR Program in Sindhupalchok}

Post-disaster reconstruction (PDR) projects often deals with uncertainties and complexity, consider one of the most challenging tasks to be deal with those involved in reconstruction of disaster-affected areas. Reconstruction program of Nepal is carrying out with very slow pace. Top down approach to design and implement post-disaster reconstruction are often influenced by non-cooperation and noncompliance of people and failure to recognise socio-economic and cultural sensitivities.

There are many challenges in ground which are creating the hindrances for smooth functioning of PDR program. Peoples and governments of Nepal itself are not fully satisfied with the speed of PDR. The major challenges of PDR in Sindhupalchok are: institutional and policy weakness, process oriented bureaucracy, lack of coordination, lack of human resource, lack of construction material, insufficient financial assistance and price hike of construction material.

\section{Impact of PDR in Socio-Economic Condition}

Reconstruction and resettlement is really imperative task of government and international community. It needs extensive preparation, collaboration with multiple stakeholders and participation of people. It is multidimensional, expensive and time consuming task. A more coherent and flexible framework for planning and managing reconstruction, supporting and making the best uses of local efforts and resources and targeted external inputs could achieve both speed and effectiveness.

Post Disaster Reconstruction is an opportunity for Build Back Better and for planned development. It can help for socio-economic improvement of beneficiaries and can change life standard of people if it carried out in effective manner. It has been revealed that socio-economic indicator like skill infrastructure development, flooring and roofing of house, sanitation, employment, earning, banking activities, development activities, education, health and living standards has been improved so far. 


\section{Conclusion}

Disaster is becoming a great threat for human, social, economic and environmental sustainability and for development. The frequency, intensity, severity and ramification of disaster are increasing day by day. The number of dead, injured, displaced and damage is also increasing, so it needs international or collective effort to cope up with.

PDR is a program of recovery and rehabilitation phase of disaster management where actions taken to restore and if possible improve pre-disaster living condition of affected communities. PDR is usually slow, expensive, complex, controversial and multidimensional issue which gives positive result only if it is carried out in well managed and synchronized, transparent and participatory approach. Build back better and linking reconstruction with development and economic activities are the fundamental and essential element of successful reconstruction. Socioeconomic condition of people can be enhanced by adopting appropriate measure in PDR.

After earthquake 2015, National Reconstruction Authority has been established and is working all over the affected area of Nepal. Sindhupalchok is one of the most affected districts by earthquake 2015, where NRA has launched its reconstruction program which is in progress but is not as successful as expected before. Majority of people has received only first phase of grant and it still takes around one year to complete reconstruction. Bureaucratic hurdles, lack of finance, trained human resource and construction material, poverty and negligence of people are major reason behind the delay of accomplishment of PDR.

Government has to execute its policy strictly and people also have to be cooperative towards the government policy and should reconstruct their house according to the policy of NRA within given timeframe. Bureaucratic efficiency, availability of trained human resource and availability of material with reasonable prize are other area where government has to take care.

\section{References}

Bang, N. H. (2012). Disaster management in Cameroon: the Lake Nyos disaster experience. Disaster Prevention and Management: An International Journal, 21(4), 489-506.

Dhungana, A., Dahal,K. R., Shrestha, S.,Thapa, N. \&Neupane, S. (2017). A review on issues associated with the shelter reconstruction after Gorkha Earthquake 2015 in Nepal.

Iuchi, K. (2010). Redefining a place to live: Decisions, planning processes and outcomes of resettlement after disasters.University of Illinois at Urbana-Champaign.

Karunasena, G., \&Rameezdeen, R. (2010). Post-disaster housing reconstruction: Comparative study of donor vs owner-driven approaches. International Journal of Disaster Resilience in the Built Environment, 1(2), 173-191.

Natural Disaster Relief Act. (1982). Retrieved January 11, 2018, from http://www.nrcs.org/sites/default/files/ pro-doc/natural-calamity-relief-act.pdf

Rafferty P. J. (2017). Nepal Earthquake of 2015, Retrieved From https://www.britannica.com/topic/nepal-earthquake-of-2015

Roosli, R., Vebry, M. OthumanMydin, M. A., \& Ismail, M. (2012).Building and planning of postdisaster rehabilitation and reconstruction. International Journal of Academic Research, 4(1).

Sharma, K., \& KC. A. (2017).Challenges of reconstruction after 2015 Nepal earthquake and a comparison with Haiti and Chile reconstruction. 
$27 \mid$ Journal of APF Command and Staff College

UNISDR Terminology on of DRR. (2009). Retrieved February 1, 2018, from Error! Hyperlink reference not valid. unisdr.org/we/ inform/ terminology

Ye, Y., \& Okada, N. (2002, July).Integrated relief and reconstruction management following a natural disaster. In Second annual IIASA-DPRI meeting, Integrated disaster risk management: megacity vulnerability and resilience. 